\title{
AC 2010-194: THE FIRSTE DECADE OF THE NEW MILLENNIUM
}

Joan Kowalski, Penn State University - New Kensington

Joan A. Kowalski earned both her Bachelors and Masters Degrees in Civil Engineering from Penn State University. In 1987, she joined the faculty at the Penn State New Kensington Campus, where she has advanced to the rank of Senior Instructor in Engineering. In 1999, she assumed the role of Program Director for the Mechanical Engineering Technology (MET) Program. She co-founded the Females Interested in Reaching for Science, Technology and Engineering (FIRSTE) Program in 1993 and continues serving as a co-director. This program is designed to attract high school females towards nontraditional careers such as engineering. Joan also displays her dedication to mentorship as advisor to the Society of Women Engineers (SWE) student chapter on campus along with advising the Tau Alpha Pi (TAP) National Honor Society for engineering technology students of the Iota Beta Chapter, Penn State New Kensington. Over the years, Joan has received numerous awards including the prestigious Penn State University's Women's Achievement Award in 2003 because of her commitment to the FIRSTE Program and other effective mentoring activities both on campus as well as within the community. In addition, Joan was the recipient of the Excellence in Teaching Award at Penn State New Kensington in 2005.

\section{Tracie L. Brockhoff, Penn State University - New Kensington}

Tracie L. Brockhoff is the Demonstration and Equipment Specialist in Biology and Chemistry at Penn State New Kensington. She has been employed full time at the campus for 24 years after having earned her Penn State degree in Science. She serves as the teaching assistant for the Anatomy and Microbiology courses and is also the course editor for the online course management system (Angel) for a variety of biology and chemistry courses. Her interests include mentoring students and helping them find their full potential through activities such as the Females Interested in Reaching for Science, Technology and Engineering (FIRSTE) Program, which she co-founded in 1993 and continues to co-direct. She is also the advisor to the Science Club on campus. 


\section{The FIRSTE Decade of the New Millennium Outcomes and Assessment}

For nearly two decades, the Females Interested in Reaching for Science, Technology and Engineering (FIRSTE) Program has directed a considerable number of young women into engineering, engineering technology and/or non-traditional science careers. Developed through the engineering and science departments at XXXX University - XXXX Campus, this program targets ninth-through eleventh-grade high school females who demonstrate both an interest and ability in mathematics and the sciences. Twelve girls are selected from a pool of typically several dozen applicants based on completion of an official application along with a written essay. Priority is given to students who are first-generation college bound, economically disadvantaged and of a minority background. This two-day on-campus event entails hands-on workshops, computer-based design, a professional/peer mentor session and a tour to a technical facility. Thus, ties to engineers and scientists from local industries for "real world" experiences as well as to math and science high school instructors for recruitment and recommendation of program participants are integral to the mission of the program. Participants who have reached collegeage have been contacted this past summer to assess the program outcomes. Specifically, roughly 75 percent of participants surveyed indicate engineering, engineering technology, or some nontraditional field of science as their intended major. One-third has chosen XXXX University, with one-fourth of this group enrolling at the XXXX XXXX Campus in particular. Feedback from the questionnaire conducted reflects a strong positive impact on the participants' interests in careers related to engineering, engineering technology and non-traditional science. In fact, a 2007 program FIRSTE participant is currently a freshman in the mechanical engineering technology (MET) program. She has been awarded the 2009-2010 Chancellor Fellow Scholarship for which she receives funding as a research assistant to engineering faculty. She, as well as nearly all of the participants, states through the survey a desire to continue reaching for achievements in the areas of science, technology and engineering.

\section{Justification for the Program}

Although women have made great strides in many career fields, they still lag far behind men in engineering. According to a study presented in the Spring 2009, Journal of College Admission, the percentage of women enrolled in engineering at the baccalaureate level is just 1213. Minorities account for a smaller percentage. At the advanced degree levels, the figures are reduced even further. This figure is rather startling considering the fact that women comprise roughly 56 percent of the undergraduate population. Lisa Tsui, author of the aforementioned reference, gathered data from six undergraduate engineering programs that enroll and graduate a significant percentage of women. She identified three common factors which appear to affect this relatively high degree of success. They are as follows:

- More female-focused recruitment opportunities are necessary;

- Community outreach fosters recruitment;

- Both recruitment and outreach efforts must include undergraduate students. ${ }^{1}$

1 Tsui, Lisa. "Recruiting Females into Male Dominated Programs: Effective Strategies and Approaches." N.p.: Journal of College Admission, 2009. Web. 
Many professional organizations such as the Society of Women Engineers (SWE) and the Women in Engineering ProActive Network (WEPAN) sponsor activities which encourage females to explore engineering as a potential career. Specifically, SWE holds an annual high school shadowing day while WEPAN works with girls age 11-17 through "The Girls, Math \& Science Partnership"'.2

At the university level, engineering schools are obtaining funding to create programs designed to educate females about career possibilities. In fact, XXXX University supports the "Women in the Sciences \& Engineering (WISE) Institute" which offers a variety of multidisciplinary programs for girls in grades 10-12. These events include a one week program at XXXX XXX, hands-on workshops and projects, and interactions with mentors from industry and academia. ${ }^{3}$ Hence, the FIRSTE Program was developed at the local level to attract females within the XXXX XXXX service area.

The FIRSTE program provides a vehicle for XXXX University and the XXXX Campus to capture the interest of this growing community of college-bound young women and to introduce them to nontraditional careers in engineering, engineering technology and science.

\section{Problem Statement}

The Registrar at the XXXX Campus reports that less than 10 percent of enrolled engineering and engineering technology students are female, and proportionately fewer are of a minority group.

The problem is twofold: (1) young women are seldom encouraged by teachers or counselors to consider or investigate careers in engineering because engineering continues to be a traditionally male choice, and (2) young women are not reached early enough to effectively prepare them for matriculation into engineering, engineering technology, or science programs.

\section{Purpose}

The objectives of the FIRSTE program are to foster involvement of females in engineering, engineering technology, and science careers by reaching them during the careerformative years and, consequently, increase recruitment efforts and enrollment at XXXX University, including XXXX XXXX. This effort is in direct relation to the XXXX Campus Recruitment and Retention Plan (Objective 3) which seeks to "integrate women from diverse educational backgrounds into the engineering, engineering technology, and science programs at the $[\mathrm{XXXX} \mathrm{XXXX]}$ Campus to ensure their success and retention." The program is also geared toward reaching minority females in particular, which addresses Campus Goal D" to provide a holistic, caring and supportive learning environment for students of all ages, races, creed and gender."

2 Eisenberg, Alissa. "Across country, more females in engineering." theDP.com. N.p., 14 Mar. 2007. Web. 25 Feb. 2010. <http://www.daileypennsylvanian.com/node/52433>.

3 "WISE Institute K-12 High School." Women in the Sciences \& Engineering Institute. Penn State, n.d. Web. 25 Feb. 2010. $<\mathrm{http} / / /$ www.equity.psu.edu/wise/k12-high.asp >. 
The XXXX Campus' size and low student-to-teacher ratio (20:1) serve to "foster student's abilities" (Goal E). In surveys conducted at the XXXX Campus, students consistently indicate that the personal interaction offered by the academic community (i.e. advising and mentoring) has enhanced their academic success. Consequently, this campus serves as an excellent transition for students who must transfer to XXXX in order to complete their degree in a four-year engineering program or, for students directly involved in the operation of machines and equipment, enrollment in one of the engineering technology programs available at the XXXX Campus.

\section{$\underline{\text { Approach }}$}

Informational program brochures and application forms are mailed to $9^{\text {th }}$ through $11^{\text {th }}$ grade students via community high school contacts. Students express an interest in the program by submitting the application form and twelve are selected. The "career undecided" and minority females are given selection preference over those who have already chosen engineering, engineering technology, or science as a career. Once selection is made and acceptance confirmed, the students and their affiliate schools are listed in a news release.

In order for the FIRSTE program to be most effective, the young girls should be undecided rather than fairly certain about their career choices. Thus, the directors, along with mentors from industry, review on a regular basis the current list of contacts, visit local high schools and community events for career-related activities in an effort to more readily attain this goal.

"Hands-on" workshops in biomedical technology, genetic research, chemical and mechanical experimentation, robotics, and solid modeling are held to stimulate an interest in, and provide a realistic view of engineering, engineering technology and science careers.

Furthermore, a field trip is conducted at a local industry so that these young women can observe the technical workplace, current methods and techniques, and professionals within their work environment. Also, female engineers and scientists from various corporations attend an informal session as part of the mentoring process provided to the participants. Finally, the attendees subdivide to complete a team-oriented computer design project. Their projects are displayed at the recognition banquet held at the end of the program, which is attended by immediate family members.

The tentative agenda for the 2010 agenda is provided in the Appendix.

\section{Outcomes}

Since implementing the FIRSTE program, several participants have selected engineering, engineering technology or science as a career of choice; for others, engineering has at least become a new or more approachable option. Because the program focuses on high school age women, measurable outcomes continue to develop. It is hoped that female engineering/science enrollment, as a direct result of the FIRSTE program, will sufficiently support continuation of the program with enthusiastic participation by XXXX XXXX students. 
The expected impact/results of program efforts are:

- To influence the attitudes of formative and impressionable young women in a positive way toward considering engineering, engineering technology and science as possible career paths.

- To introduce computer-based design used in the field of engineering, engineering technology and science.

- To offer the experience of practical laboratory applications in conjunction with technical laboratory reports.

- To stimulate critical thinking skills as a preparation for college study in engineering, engineering technology and science.

- To strengthen decision-making skills for exploring the changing academic and career opportunities which exist for college-bound students, through interaction with female role models currently employed in engineering, engineering technology and science.

- To introduce prospective students and their families to XXXX XXXX, regardless of career choice.

- To involve the parents in order to impact their attitudes and serve as an informational source of possibilities for women in the fields of engineering, engineering technology and science.

- To increase the enrollment of females in the engineering, engineering technology and science programs at XXXX XXXX.

- To increase enrollment of minority females in engineering, engineering technology and science programs at XXXX XXXX.

\section{Evaluation}

Program success will be measured and tracked annually through the following indicators:

- The eventual enrollment of participants at XXXX XXXX.

- A survey will be conducted to assess the value of the program from the participants' perspective regarding the program's impact on their personal career options.

Furthermore, performance in subsequent high school mathematics, computer and science courses will be acknowledged.

- Informal feedback will be elicited from the parents who attend the recognition dinner.

- After matriculation at XXXX XXXX, additional research efforts could be made to compare participating students with non-participating females of similar backgrounds, as measured by their respective academic performance and successful completion of their academic program.

- Evaluation efforts will be modified as needed to enhance value and reliability as additional students participate in this annual effort.

\section{Measurement of Objectives}

The objective of increasing interest by females in science, technology and engineering was measured by observation and verbal feedback from the young women and their parents at a closing program and completion of an evaluation form by each participant prior to their departure. A follow-up telephone call will also be made to those of them next year who will be 
ready to attend college then. At present, the young women felt the program provided them with plenty of information as they ponder career choices.

No official survey was distributed to the parents because they were directly involved in the recognition dinner only. All parents and family members expressed their support for this kind of program and extended sincere appreciation for the committee's efforts.

\section{Long Term Results of FIRSTE}

For the past seventeen years, the FIRSTE Program has directed a considerable number of participants toward actually selecting engineering, science or technology as a career of choice. For others, these fields of study have at least become viable options.

This summer, all FIRSTE participants who have graduated from high school this year were surveyed by phone. Their responses, along with those from previous surveys, have been compiled into the statistics shown in the following table. All nine participants from the 20062008 FIRSTE Programs who have reached college age have been contacted. These contacts bring the total number reached to 167 out of a possible 171 for college-ready FIRSTE participants. Over seventy percent have selected a career in the engineering, engineering technology, or science area. This number accounts for almost three-quarters of all the eligible participants reached for comment. Less than twenty percent selected some other career choice, while a mere seven percent were undecided at the time of high school graduation.

Nearly one-third of eligible participants have committed to XXXX, with over one-quarter of these students bound for the XXXX XXXX location specifically. In fact, one of these recent graduates is attending $\mathrm{XXXX} \mathrm{XXXX}$ for mechanical engineering technology. She has been awarded the Chancellor's Scholarship which will require her to serve as a research assistant to both FIRSTE Program Directors with regard to each of their own specific projects. Other participants who graduated from high school in 2009 have chosen to major in civil, mechanical and chemical engineering as well as in a variety of science-related fields such as botany, biochemistry and zoology.

Regardless of the individual career choices made, it is evident that all FIRSTE participants found this exposure to the technical world with professional women to be exciting and encouraging, thereby removing some of the anxiety surrounding careers in the math and science fields. As expressed by Kayla Schrecengost, FIRSTE 2009 participant, "The FIRSTE Program is a great way to learn about several different careers in the science and engineering fields. It opens the door for the possibilities women can choose as a career."

The FIRSTE Program has impressed, however, more than just its own participants. It has become an integral piece of a regional collaborative effort known as the Westmoreland Economic Development Initiative for Growth (WEDIG) through alliances with the Pennsylvania Prosperity Partnerships. XXXX XXXX has taken the lead role in establishing this alliance between industry, government, education and the community entities. As a result, the ALCOA Foundation announced in October 2009 a \$70,000 investment in XXXX XXXX to augment K12 STEM learning. Stem initiatives are designed to increase the number of students, especially females, minorities and the underrepresented, in the fields of science, technology, engineering and math. The education committee has deemed the FIRSTE Program an important piece of this 
STEM initiative and, thus, plans to form a complimentary program aimed at females in grades 78. Moreover, this plan intends to use former FIRSTE program participants as mentors to those younger students in this newly proposed program. ${ }^{4}$

\section{Participant Survey (Results)}

\begin{tabular}{|c|c|c|c|c|c|c|c|c|c|c|c|}
\hline \multirow{3}{*}{$\begin{array}{l}\text { FIRSTE } \\
\text { Program } \\
\text { Year }\end{array}$} & \multicolumn{7}{|c|}{ Career Choice } & \multicolumn{4}{|c|}{ University Choice } \\
\hline & \multirow[t]{2}{*}{$\begin{array}{c}\text { Eligible to } \\
\text { Attend college } \\
\text { as of Fall ' } 09\end{array}$} & \multicolumn{2}{|c|}{$\begin{array}{c}\text { Engineering/ } \\
\text { Technology/ } \\
\text { Science } \\
\text { Majors }\end{array}$} & \multicolumn{2}{|r|}{$\begin{array}{c}\text { Other } \\
\text { Majors }\end{array}$} & \multicolumn{2}{|c|}{ Undecided } & \multicolumn{2}{|r|}{$\mathbf{X X X X}$} & \multicolumn{2}{|r|}{$\begin{array}{l}\mathbf{X X X X} \\
\mathbf{X X X X}\end{array}$} \\
\hline & & No. & $\%$ & No. & $\%$ & No. & $\%$ & No. & $\%$ & No. & $\%$ \\
\hline 1993 & 12 & 7 & $7 / 12=58.3$ & 5 & $5 / 12=41.7$ & 0 & $0 / 12=0$ & 2 & $2 / 12=16.7$ & 1 & $1 / 2=50$ \\
\hline 1994 & 12 & 9 & $9 / 12=75$ & 3 & $3 / 12=25$ & 0 & $0 / 12=2$ & 4 & $4 / 12=33.3$ & 1 & $1 / 4=25$ \\
\hline 1995 & 12 & 9 & $9 / 12=75$ & 3 & $3 / 12=25$ & 0 & $0 / 12=0$ & 4 & $4 / 12=33.3$ & 1 & $1 / 4=25$ \\
\hline 1996 & $11 *$ (use 10$) * *$ & 4 & $4 / 10=40$ & 6 & $6 / 10=60$ & 0 & $0 / 10=0$ & 2 & $2 / 10=20$ & $1 \#$ & $1 / 2=50$ \\
\hline 1997 & 12 & 10 & $10 / 12=83.3$ & 2 & $2 / 12=16.7$ & 0 & $0 / 12=0$ & 6 & $6 / 12=50$ & 2 & $2 / 6=33.3$ \\
\hline 1998 & 12 & 11 & $11 / 12=91.6$ & 1 & $1 / 12=8.3$ & 0 & $0 / 12=0$ & 4 & $4 / 12=33.3$ & 0 & $0 / 4=0$ \\
\hline 1999 & $12 *$ (use 11$) * *$ & 10 & $10 / 11=90.9$ & 1 & $1 / 11=9$ & 0 & $0 / 11=0$ & 6 & $6 / 11=54.5$ & 1 & $1 / 6=9$ \\
\hline 2000 & 12 (use 11 )** & 7 & $7 / 11=64$ & 0 & $0 / 11=0$ & 4 & $4 / 11=36$ & 1 & $1 / 11=10$ & 0 & $0 / 1=0$ \\
\hline 2001 & $11 *($ use 10$)$ & 5 & $5 / 10=50$ & 3 & $3 / 10=30$ & 2 & $2 / 10=20$ & 4 & $4 / 10=40$ & 0 & $0 / 1=0$ \\
\hline 2002 & 12 & 9 & $9 / 12=75.0$ & 2 & $2 / 12=16.7$ & 1 & $1 / 12=8.3$ & 4 & $4 / 12=33.3$ & 2 & $2 / 4=50.0$ \\
\hline 2003 & $12 *($ use 11$)$ & 11 & $11 / 11=100.0$ & 0 & $0 / 11=0.00$ & 0 & $0 / 11=0.00$ & 4 & $4 / 11=36.4$ & 1 & $1 / 4=25$ \\
\hline 2004 & $12 * *($ use 11$)$ & 6 & $6 / 11=54.5$ & 2 & $2 / 11=18.2$ & 3 & $3 / 11=27.3$ & 2 & $2 / 11=18.2$ & 0 & $0 / 2=0$ \\
\hline 2005 & $12 *($ use 11$)$ & 10 & $10 / 11=90.9$ & 1 & $1 / 11=9.1$ & 0 & $0 / 11=0$ & 4 & $4 / 11=36.4$ & 0 & $0 / 4=0$ \\
\hline 2006 & $12 * *$ (use 11 ) & 9 & $9 / 11=81.8$ & 1 & $1 / 11=9.1$ & 1 & $1 / 11=9.1$ & 4 & $4 / 11=36.4$ & 0 & $0 / 4=0$ \\
\hline 2007 & $6 * *$ (use 5) & 4 & $4 / 5=80$ & 0 & $0 / 5=0$ & 1 & $1 / 5=20$ & 2 & $2 / 5=40$ & 2 & $2 / 2=100$ \\
\hline 2008 & 4 & 3 & $3 / 4=75$ & 1 & $1 / 4=25$ & 0 & $0 / 4=0$ & 1 & $1 / 4=25$ & 1 & $1 / 1=100$ \\
\hline 2009 & $* * *$ & & & & & & & & & & \\
\hline Totals & 171 (use 167) & 124 & $124 / 167=74.3$ & 31 & $31 / 167=18.6$ & 12 & $12 / 167=7.2$ & 54 & $54 / 167=32.2$ & 13 & $13 / 54=24.1$ \\
\hline
\end{tabular}

* Missing participant due to last minute cancellation.

** Participant unable to be reached for comment

*** Information available Summer 2010

\# Deceased, Spring 1998

4 "WEDIG." Penn State New Kensington. Penn State New Kensington, 23 Feb. 2010. Web. 25 Feb. 2010. $<$ http://www.nk.psu.edu/43090.htm>. 


\section{Cost of Program}

The total cost of the FIRSTE Program for 2009 was $\$ 9,609.31$. This figure includes new equipment (bridge truss construction kit with computer software interfacing by PASCO) for usage in a structural design session. This particular expense totaled $\$ 3,143.52$. Funding from a variety of sources (both internal and external) ensured the success of the FIRSTE Program again this summer. These contributors are listed on the back cover of the program brochure. 


\section{$\underline{\text { Appendix \#1 }}$}

\begin{tabular}{|c|c|c|}
\hline & $\begin{array}{l}2010 \text { FIRSTE Program Agenda } \\
\text { Wednesday, May 12, } 2010\end{array}$ & \\
\hline $7: 30-7: 45$ AM & Arrival/Registration/Continental Breakfast & Joan Kowalski /Tracie Brockhoff \\
\hline \multirow[t]{2}{*}{ 8:00 - 8:15 AM } & Welcome/Agenda Setting & Kevin Snider/Arlene Hall \\
\hline & & Joan Kowalski /Tracie Brockhoff \\
\hline $8: 15-8: 45$ AM & Check In at Apartments & Tracie Brockhoff \\
\hline $8: 45-9: 15$ AM & Getting Acquainted with Clickers & Deborah Sillman \\
\hline 9:15 -9:30 AM & Careers in Agriculture & Sarah Brockhoff/ \\
\hline 9:30 - 10:15 AM & Biomedical Engineering Technology (Rm 18 Eng) & Samantha Bukovac \\
\hline 10:15 - 10:30 AM & Break & \\
\hline $10: 30-12: 00 \mathrm{PM}$ & Robotics (Rm 127 Tech) & Rick Evanuik \\
\hline $12: 00-12: 30 \mathrm{PM}$ & Lunch & \\
\hline $12: 30 \mathrm{PM}$ & Financial Aid & Amy Blakley \\
\hline $12: 45-1: 15$ PM & Lion Ambassador Tour of PSNK & \\
\hline 1:15PM & Leave for Tour & \\
\hline 2:00 PM & Tour of Invention Land & RIDC Park, Blawnox \\
\hline 4:00 PM & Depart & \\
\hline 4:30 PM & Arrival at Campus & \\
\hline 5:30 PM & Meet and Greet with Mentors & \\
\hline $6: 00-6: 30 \mathrm{PM}$ & Dinner (Cafeteria) & \\
\hline 6:30 - 9:30 PM & Mentoring Session (Cafeteria) & \\
\hline
\end{tabular}

Residential Supervisors: Amanda Moore, Susan Palumbo, Deanna Mazur, Natalie Fisher, Stephanie Powell

\section{Thursday, May 13, 2010}

$\begin{aligned} \text { 7:30 - 8:00 AM } & \text { Continental Breakfast } \\ \text { 8:00-8:45 AM } & \text { Radiological Sciences (Rm 19 Eng) } \\ \text { 8:45-10:45 PM } & \text { Green Chemistry/Alternative Energy Sources (Rm 124 Eng)) } \\ \text { 10:45-12:00 PM } & \text { Arboretum Exploration - (Rm 7 Sc) } \\ \text { 12:00-12:45 PM } & \text { Lunch - Admissions } \\ \text { 12:45-1:30 PM } & \text { A Virtual Day with the Vet (Rm 20 Sc) } \\ \text { 1:30-2:45 PM } & \text { Bridge/Truss Analysis } \\ \text { 2:45-3:00 PM } & \text { Break } \\ \text { 3:00-3:30 PM } & \text { Introduction to Solidworks (44G/F Blissell) } \\ \text { 3:30-4:45 PM } & \text { Creative Design Project (44G/F Blissell) } \\ \text { 4:45-5:00 PM } & \text { Program Evaluations }\end{aligned}$

Debbie Majetic

Dr. Robert Mathers/Susan Palumbo Deborah Sillman/Dr. Hamilton Alana Keister/Nancy Burns Dr. Becky Morrow Natalie Fisher/Stephanie Powell Nick Petrucci/Natalie Fisher/Steph Powell Nick Petrucci/Natalie Fisher/Steph Powed 
5:00 - 5:45 PM

6:00 PM

6:30 - 8:00 PM
Break - Get ready for dinner

Participants and Parents arrive for dinner

Recognition Dinner (Conference Building - Rm 51)
Dr. Jane Viti 